\title{
Prevalence of post partum modern family planning utilization and associated factors among postpartum mothers in Debre Tabor town, North West Ethiopia, 2018
}

\author{
Eden Bishaw Taye, Dawit Gebeyehu Mekonen and Tibeb Zena Debele* (1)
}

\begin{abstract}
Objective: The aim of this study was to assess the prevalence of postpartum modern family planning utilization and associated factors among postpartum mothers in Debre Tabor town, North West Ethiopia, 2018.

Result: The proportion of postpartum modern contraceptive utilization in Debre Tabor town was 63\% (95\% Cl 59\%, 67.4\%). In multivariable logistic regression analysis; age of the mother (25-29) [AOR: 2.004 (95\% Cl 1.079, 3.722)], married women [AOR $4.804(95 \% \mathrm{Cl} 1.843,12.521)]$, return of menses [AOR: $3.639(95 \% \mathrm{Cl} 2.454,5.396)$ ] and previous history of family planning [AOR: 2.409 (95\% Cl 1.474, 3.937)] were the factors positively associated with utilization of postpartum modern contraceptive.
\end{abstract}

Keywords: Postpartum family planning, Cross-sectional study, Debre Tabor town

\section{Introduction}

Postpartum family planning (PPFP) is the prevention of unintended and closely spaced pregnancies through the first 12 months following childbirth [1]. Thus, after delivery mothers are counseled and encouraged to initiate modern contraceptive method with in the specified period.

If a women had only the number of pregnancies they wanted, at the intervals they wanted, maternal mortality would drop by $30 \%$ [2]. Family planning (FP) can avert 3.2 million out of 5.6 million under five deaths and 109,000 out of $155,000(70 \%)$ of maternal deaths. However, A Demographic health survey data from 57 countries indicated that, right after delivery $62 \%$, after 6 months of amenorrhea $43 \%$ and at the end of amenorrhea $32 \%$ of women in the first year after birth have an unmet need for contraception [3].

*Correspondence: zenatibeb@gmail.com

Department of Midwifery, College of Medicine and Health Science,

University of Gondar, P.O. Box 196, Gondar, Ethiopia
If a woman is amenorrhic, fully or nearly fully breast feeding and in the first 6 months of delivery, the risks of getting pregnant will be reduced by $98 \%$. Therefore, post-partum mothers have a special privilege of using lactational amenorrhea (LAM) as one of the alternatives of family planning methods [1-3]. The 6 th month period however, is a hallmark of shifting from exclusive breastfeeding to complementary feeding [1]. It is also a period where LAM users should shift to other modern contraceptives methods.

Pregnancies that occur in the first year of the delivery are mostly unplanned and risky for the mothers. It also results in adverse birth outcomes for the babies such us, preterm, low birth weight, and small for gestational age $[2,4]$. If couples spaced their pregnancies at least 2 years apart from the previous birth, the morbidity and mortality risk both for the mothers and their babies will be reduced. In addition, spacing births allows parents to devote more time to each child in the early years $[5,6]$.

Although the majority of postpartum women indicated the desire to delay the next birth; mostly, either family planning methods are not offered to, or taken up by the 
women adequately after delivery or in the first year of postpartum [7].

Therefore, this research tries to assess the prevalence and factors associated with the PPFP utilization there by help policy makers create a strategy to tackle the problem and increase the CPR as high as possible and improve the quality of life both for the mother and her new born baby.

\section{Main text \\ Methods \\ Study design and setting}

A community-based cross-sectional study was conducted from September 20 to October 20, 2018, at Debre Tabor town which is the capital city of South Gondar zone Amhara regional state, North West Ethiopia. Based on the 2007 National Census conducted by Central Statistical Agency of Ethiopia (CSAE) projection, the town has a total population of 55,596 of whom 27,644 (49.7\%) were male and 27,952 (50.3\%) were female. From the total population, $96.72 \%$ are Orthodox Christian, and $2.54 \%$ are Muslim [8].

\section{Sample size and sampling procedure}

Post-partum women between 6 and 12 months of delivery who are permanent residents of Debre Tabor town were included in the study. A single population proportion formula was used to calculate the sample size of 550. The following assumptions were made to calculate the sample size, magnitude of PPFP utilization 68.1\% [9] from a previous study, $95 \%$ confidence interval, $5 \%$ margin of error, a design effect of 1.5 and nonresponse rate of $10 \%$. Three out of the six Kebeles (kebele1, kebele2, and kebele5) were selected by simple random sampling Then, the study participants were all mothers between 6 and 12 months of delivery in the selected Kebeles.

\section{Operational definitions}

Postpartum period: The period between 6 and 12 months of delivery [9].

Utilization of PPFP: If a woman is using any one of the following modern contraceptive methods between 6 and 12 months following her recent childbirth: pill, intrauterine device, injectable, condom (men or women), women sterilization, implants $[9,10]$.

\section{Data collection instrument and process}

Data were collected by face-to-face interview using a structured and pre-tested questionnaire. The questionnaire was prepared in English, translated to Amharic and translated back to English. The data collection was performed by six diploma midwives and supervised by two MSc midwives.

\section{Data analysis}

Data were entered with epi-info 7 and analyzed using SPSS version 20. Bivariate and multivariable logistic regression analyses were conducted to identify predictors for PPFP utilization. Variables found to be significant on Bivariate analysis $(\mathrm{P}<0.2)$ were included in the multivariable model. Adjusted odds ratios and $95 \%$ confidence intervals were generated. Probability values $<0.05$ were considered statistically significant.

\section{Results}

\section{Socio-demographic characteristics}

From a total of 563 postpartum mothers in the selected Kebeles, 546 mothers were included in the study, making a response rate of $97 \%$. The mean age of the respondent's was 27.57 years with SD of 4.781 . From the participants, 519 (95.1\%) were married (Table 1).

\section{Reproductive and reproductive health service-related characteristics}

Among the respondents, 407 (74.5\%) had one to two live births. Four hundred fourteen (75.8\%) of the respondents reported that they had a spontaneous vaginal delivery. About 426 (78\%) of the mothers had an intention of having another child in the future. Mothers with a history of a rerun of menses were 300 (54.9\%) (Table 2).

Among the contraceptive utilizers, injectables were the most commonly used methods accounting for 213 (60.2\%) of the total utilization, followed by pills $28 \%$, implants and IUD 9.9\% and IUD 1.1\% respectively.

Different reasons where mentioned for non-utilization. This includes, unreturning of menses 82 (42.7\%) lack of sexual initiation $19.3 \%$ the need to have more children $14.6 \%$ and fear of contraceptive side effects $12.7 \%$. Majority of the mothers $208(86.7 \%)$ received counseling about PPFP services from ANC clinics, $22.9 \%$ from health extension workers and $14.6 \%$ from the family planning clinics before the last child was delivered. On the other hand, $56.5 \%$ got PPFP counseling from labor and delivery ward $34.9 \%$, from immunization clinic, $25.8 \%$ from PNC and 19.1\% from health extension worker after the delivery of the last child.

\section{Factors associated with postpartum family planning utilization}

On bivariate analysis, the factors found to be significantly associated with utilization of PPFP were: age of the mothers, marital status of the mother, educational status of the mother, abortion, a return of menses, intention to have another child and previous history of family planning utilization. 
Table 1 Socio-demographic characteristics of postpartum mother at Debre Tabor town, south Gondar zone, North West Ethiopia, $2018(n=546)$

\begin{tabular}{|c|c|c|c|}
\hline Variables & Category & Frequency & Percent \\
\hline \multirow[t]{4}{*}{ Age } & $\leq 24$ & 130 & 23.8 \\
\hline & $25-29$ & 246 & 45.1 \\
\hline & $30-34$ & 105 & 19.2 \\
\hline & $\geq 35$ & 65 & 11.9 \\
\hline \multirow[t]{2}{*}{ Marital status } & Married & 519 & 95.1 \\
\hline & Others $^{\mathrm{a}}$ & 27 & 4.9 \\
\hline \multirow[t]{3}{*}{ Religion } & Orthodox & 529 & 96.9 \\
\hline & Muslim & 15 & 2.7 \\
\hline & Others $^{\mathrm{b}}$ & 2 & 0.4 \\
\hline \multirow[t]{4}{*}{ Level of education } & No formal education & 113 & 20.7 \\
\hline & Primary & 92 & 16.8 \\
\hline & Secondary & 141 & 25.8 \\
\hline & Tertiary & 200 & 36.6 \\
\hline \multirow[t]{5}{*}{ Occupation } & Housewife & 331 & 60.6 \\
\hline & Government and private employed & 112 & 20.5 \\
\hline & Laborer & 6 & 1.1 \\
\hline & Self-employed & 61 & 11.2 \\
\hline & Others ${ }^{c}$ & 36 & 6.6 \\
\hline \multirow[t]{4}{*}{ Partners educational status $(N=532)$} & No formal education & 101 & 19.0 \\
\hline & Primary education & 71 & 13.3 \\
\hline & Secondary education & 131 & 24.6 \\
\hline & Tertiary education & 229 & 43 \\
\hline \multirow[t]{4}{*}{ Partners occupation ( $\mathrm{N}=532)$} & Gov't employed and private employed & 261 & 49.1 \\
\hline & Laborer & 59 & 11.1 \\
\hline & Self-employed & 186 & 35 \\
\hline & Others ${ }^{c}$ & 26 & 4.9 \\
\hline
\end{tabular}

a Others include single, widowed, and divorced

b Others include protestant and catholic

c Others include farmer, student

From the variables found to be significant in the bivariate analysis; age of the mothers (25-29) [AOR: 2.004 (95\%CI 1.079, 3.722)], marital status (married) [AOR 4.804 (95\% CI 1.843, 12.521)], return of menses [AOR: 3.639 (95\% CI 2.454, 5.396)] and previous history of family planning utilization [AOR: 2.409 (95\% CI $1.474,3.937)]$ were found to be significantly associated with utilization of postpartum family planning in multiple logistic regression analysis (Table 3 ).

\section{Discussion}

Even though post-partum family planning utilization plays a major role in decreasing unmet need and avoid shortly spaced births, still the utilization is very low.

This study showed that the prevalence of PPFP utilization was $63 \%$ (95\% CI 59\%, 67.4\%) which is lower than the studies done at Addis Ababa, Ethiopia 80.3\% [11], at
Ntchisi District Hospital, Malawi 74.6\% [12], the County hospital in rural Kenya 86.3\% [13]. This might be due the difference in the socio-demographic characteristics of the respondents, the time gap of the studies and the difference in the study design; in which the last two studies were institutional based studies. It could also be due to the difference in the definition of PPFP utilization in which our study included only modern methods of contraception whereas the first study incorporated traditional as well as modern family planning method use to define utilization status.

On the other hand, the finding was higher than studies that were done in Burundi 20\%, Rwanda 51\%, Uganda (28\%), at Gondar town, Ethiopia (48.4\%) and at Kebribeyah Town Ethiopia (12.3\%), [14-17]. This might be due to the differences in socio-demographic characteristics and types of data used in which the former two 
Table 2 Reproductive and reproductive health service-related history of postpartum mother at Debre Tabor town, South Gondar zone, North West Ethiopia, 2018 ( $n=546)$

\begin{tabular}{|c|c|c|c|}
\hline Variables & Category & Frequency & Percent \\
\hline \multirow[t]{3}{*}{ Parity } & $1-2$ & 407 & 74.5 \\
\hline & $3-4$ & 122 & 22.3 \\
\hline & $\geq 5$ & 17 & 3.1 \\
\hline \multirow[t]{3}{*}{ No of a live child } & $1-2$ & 414 & 75.8 \\
\hline & $3-4$ & 117 & 21.4 \\
\hline & $\geq 5$ & 15 & 2.7 \\
\hline \multirow[t]{2}{*}{ Do you have an abortion } & Yes & 51 & 9.3 \\
\hline & No & 495 & 90.7 \\
\hline \multirow[t]{2}{*}{ Type of abortion $(\mathrm{N}=51)$} & Spontaneous & 39 & 76.5 \\
\hline & Induced & 12 & 23.5 \\
\hline \multirow[t]{2}{*}{ No of abortion $(\mathrm{N}=51)$} & Once & 46 & 90.2 \\
\hline & Two times & 5 & 9.8 \\
\hline \multirow[t]{2}{*}{ Delivery place } & Institutional delivery & 532 & 97.4 \\
\hline & Home delivery & 14 & 2.6 \\
\hline \multirow[t]{2}{*}{ Mode of delivery } & Spontaneous delivery & 414 & 75.8 \\
\hline & Non-spontaneous delivery & 132 & 24.2 \\
\hline \multirow[t]{2}{*}{ Intention to have another child } & Yes & 426 & 78 \\
\hline & No & 120 & 22 \\
\hline \multirow[t]{2}{*}{ Discussed with their husband about FP } & Yes & 234 & 42.9 \\
\hline & No & 312 & 57.1 \\
\hline \multirow[t]{3}{*}{ Time interval b/n last and present child $(\mathrm{N}=319)$} & $\leq 2$ years & 51 & 16 \\
\hline & $2.1-3.9$ years & 69 & 21.6 \\
\hline & $\geq 4$ years & 199 & 62.4 \\
\hline \multirow[t]{2}{*}{ Do you have ANC visit for the last pregnancy } & Yes & 533 & 97.6 \\
\hline & No & 13 & 2.4 \\
\hline \multirow[t]{2}{*}{ No of ANC visit for last pregnancy $(\mathrm{N}=533)$} & $\geq 4$ times & 460 & 86.3 \\
\hline & $<4$ times & 73 & 13.7 \\
\hline \multirow[t]{2}{*}{ Attend PNC for the last child } & Yes & 310 & 56.8 \\
\hline & No & 236 & 43.2 \\
\hline \multirow[t]{2}{*}{ Menses return } & Yes & 300 & 54.9 \\
\hline & No & 246 & 45.1 \\
\hline \multirow[t]{4}{*}{ Time of menses return $(\mathrm{N}=300)$} & $1-3$ months & 178 & 59.3 \\
\hline & $4-6$ months & 76 & 25.3 \\
\hline & 7-9 months & 24 & 8 \\
\hline & 10-12 months & 22 & 7.3 \\
\hline \multirow[t]{2}{*}{ Resume sexual intercourse } & Yes & 499 & 91.4 \\
\hline & No & 47 & 8.6 \\
\hline \multirow[t]{4}{*}{ Time resume sexual intercourse $(\mathrm{N}=499)$} & $1-3$ months & 445 & 89.2 \\
\hline & $4-6$ months & 49 & 9.8 \\
\hline & 7-9 months & 4 & 0.8 \\
\hline & 10-12 months & 1 & 0.2 \\
\hline \multirow[t]{2}{*}{ Currently, use modern contraceptive } & Yes & 344 & 63 \\
\hline & No & 202 & 37 \\
\hline \multirow[t]{2}{*}{ Information about PPFP before delivery } & Yes & 240 & 44.0 \\
\hline & No & 306 & 56.0 \\
\hline \multirow[t]{2}{*}{ Information about PPFP after delivery of the last child } & Yes & 209 & 38.3 \\
\hline & No & 337 & 61.7 \\
\hline
\end{tabular}


Table 2 (continued)

\begin{tabular}{llcc}
\hline Variables & Category & Frequency & Percent \\
\hline When do you get $(\mathrm{N}=209)$ & Within 24 h of delivery & 106 & 11 \\
& $3-42$ postpartum days & 92 & 50.7 \\
History of FP & After 42 PP days & 451 & 44 \\
& Yes & 95 & 82.6 \\
\hline
\end{tabular}

Table 3 Bivariate and multivariable logistic regression analysis of factors associated with utilization of postpartum family planning at Debra Tabor town, South Gondar zone, North West Ethiopia, 2018 ( $n=546)$

\begin{tabular}{|c|c|c|c|c|c|}
\hline \multirow[t]{2}{*}{ Variables } & \multirow[t]{2}{*}{ Category } & \multicolumn{2}{|c|}{ PPFP utilization } & \multirow[t]{2}{*}{ COR $(95 \% \mathrm{Cl})$} & \multirow[t]{2}{*}{ AOR $(95 \% \mathrm{Cl})$} \\
\hline & & Users & Non-users & & \\
\hline \multirow[t]{4}{*}{ Age } & $\leq 24$ & 92 & 38 & $2.207(1.192-4.088)^{*}$ & $1.746(0.88-3.461)^{*}$ \\
\hline & $25-29$ & 166 & 80 & $1.892(1.086-3.296)$ & $2.004(1.079-3.722)$ \\
\hline & $30-34$ & 52 & 53 & $0.895(0.482-1.661)$ & $0.091(0.456-1.815)$ \\
\hline & $\geq 35$ (ref) & 34 & 31 & & \\
\hline \multirow[t]{2}{*}{ Marital status } & Married & 337 & 182 & $5.29(2.196-12.747)^{* *}$ & $4.804(1.843-12,521)^{* *}$ \\
\hline & Others (ref) & 7 & 20 & & \\
\hline \multirow[t]{4}{*}{ Educational status } & No formal education (ref) & 57 & 56 & $*$ & \\
\hline & Primary education & 66 & 26 & $2.494(1.39-4.476)$ & $1.639(0.842-3.191)$ \\
\hline & Secondary education & 86 & 55 & $1.536(0.931-2.534)$ & $1.05(0.595-1.854)$ \\
\hline & Tertiary education & 135 & 65 & $2.040(1.272-3.274)$ & $1.117(0.649-1.923)$ \\
\hline \multirow[t]{2}{*}{ Previous Abortion } & Yes & 22 & 29 & $0.408(0.227-0.731)$ & $0.572(0.3-1.092)$ \\
\hline & No (ref) & 322 & 173 & & \\
\hline \multirow[t]{2}{*}{ Mode of delivery } & Spontaneous (ref) & 254 & 160 & & \\
\hline & Non-spontaneous delivery & 90 & 42 & $1.35(0.89-2.047)$ & $1.224(0.769-1.946)$ \\
\hline \multirow[t]{2}{*}{ Intention to have another child } & Yes & 278 & 148 & $1.537(1.019-2.319)^{*}$ & $1.015(0.615-1.674)$ \\
\hline & No (ref) & 66 & 54 & & \\
\hline \multirow[t]{2}{*}{ ANC } & Yes & 339 & 194 & $2.796(0.902-8.665)$ & $2.256(0.646-7.873)$ \\
\hline & No (ref) & 5 & 8 & & \\
\hline \multirow[t]{2}{*}{ PNC } & Yes & 204 & 106 & $1.32(0.93-1.873)$ & $1.138(0.766-1.692)$ \\
\hline & No (ref) & 140 & 96 & & \\
\hline \multirow[t]{2}{*}{ Return of menses } & Yes & 229 & 71 & $3.674(2.549-5.295)^{* *}$ & $3.639(2.454-5.396)^{* *}$ \\
\hline & No (ref) & 115 & 131 & & \\
\hline \multirow[t]{2}{*}{ Previous history of FP } & Yes & 302 & 149 & $2.558(1.631-4.011)^{* *}$ & $2.409(1.474-3.937)^{* *}$ \\
\hline & No (ref) & 42 & 53 & & \\
\hline
\end{tabular}

Others: single, divorced and widowed

The italic signifies $\mathrm{P}<0.05$

${ }^{*}$ P-value $<0.05$

**P-value $\leq 0.001$

studies used secondary data but the data for our study was a primary. The time gap between the studies might also play a role for the observed differences. Women age 25-29 were more likely to utilize PPFP than their older counter parts. The result is supported by studies conducted at the County hospital in rural Kenya, Uganda, Nigeria and Gondar town Northern Ethiopia [13-15,
18]. This might be due the fact that younger women have more frequent ANC follow up that increased the chance of getting information about PPFP. In addition, older age women may think they could not get pregnant as they are getting older that intern may lower the utilization. 
On the contrary, the study conducted in Malawi, showed that there is increased utilization of postpartum family planning as the mother gets older [12]. This difference might be due to the difference in the in culture and socio-economic status of women.

In this study, married mothers were 4.8 times more likely to use postpartum modern contraceptives. This is in line with the study done at Addis Ababa [11]. This might be due to, since married women lived with their husbands, they might start regular sexual intercourse earlier than the non-married couples that may necessitate utilization of PPFP to program the birth of the next child. Mothers whose menses returned were 3.6 times more likely to utilize modern contraceptives. This is in consistency with literatures done in Addis Ababa, Gondar, Northwest Ethiopia, Northern Ethiopia, Gondar town, Gozamen District, East Gojam Zone, Northwest Ethiopia, and Debra Birhan town [11, 15, 19-21]. This could be due to the cultural believe that a return of fertility only occurs along with the return of menses.

Mothers who used modern family planning method before the birth of the indexed child were 2.4 times more likely to utilize PPFP. This is also supported by the study conducted at Addis Ababa, Ethiopia [11]. This could be due to women who have prior family planning utilization has a better understanding of the different types of family planning methods along with the merits and demerits that will enhance their decision making skill towards PPFP utilization. They may also have good attitude towards utilization of family planning.

\section{Limitations}

Utilization status was determined at a point in time which may slightly lower the prevalence.

\begin{abstract}
Abbreviations
ANC: ante natal care; AOR: adjusted odds ratio; Cl: confidence interval; COR: crud odds ratio; CPR: contraceptive prevalence rate; DHS: Demographic Health Survey; FP: family planning; LAM: lactation amenorrhea method; $\mathrm{MCH}$ : maternal and child health; MDG: millennium development goal; PNC: post natal care; PPFP: post-partum family planning; SPSS: statistical package for social scientists; WHO: World Health Organization.
\end{abstract}

\section{Acknowledgements}

We are very grateful to the University of Gondar for approval of the ethical clearance, technical and financial support of this study. We are also grateful to the Amhara regional state referral hospitals administrators for their permission by giving us a support letter to undertake the study.

\section{Authors' contributions}

TZ, EB involved in the conception and design of the study, participated in data collection, analyzed the data and drafted the manuscript and approve the final version of the manuscript. DG approved the proposal with some revisions, participated in data analysis and interpretation revised subsequent drafts of the manuscript and approve the last version of the manuscript. All authors read and approved the final manuscript.

\section{Funding}

The funding source of this research was the University of Gondar and the University has no role in design, data collection, analysis, decision to publish as well as preparation of the manuscript.

\section{Data availability}

The authors declare that the data regarding this manuscript can be accessed as per the request of any interested body and can be submitted for publication in Spring Nature as supplementary materials.

\section{Ethics approval and consent to participate}

Ethical clearance was obtained from the School of Midwifery under the delegation from Ethical Review Board of the University of Gondar. Written consent was obtained from each study participants after informing the objective of the study. In the consent, statements about potential risk, benefit, and confidentiality were included. Ethics committee approval was obtained for this written consent.

\section{Consent for publication}

Not applicable.

\section{Competing interests}

The authors declare that they have no competing interests.

Received: 28 February 2019 Accepted: 11 July 2019

Published online: 17 July 2019

\section{References}

1. WHO. Programming strategies for postpartum family planning. 2013.

2. Cleland J, Conde-Agudelo A, Peterson H, Ross J, Tsui A. Contraception and health. Lancet. 2012;380(9837):149-56.

3. Rossier C, Bradley SE, Ross J, Winfrey W. Reassessing unmet need for family planning in the postpartum period. Stud Fam Plan. 2015;46(4):355-67.

4. Ahmed S, Norton M, Williams E, Ahmed S, Shah R, Begum N, et al. Operations research to add postpartum family planning to maternal and neonatal health to improve birth spacing in Sylhet District, Bangladesh. Glob Health Sci Pract. 2013;1(2):262-76.

5. Smith R, Ashford L, Gribble J, Clifton D. Family planning saves lives. 2009

6. Rutstein SO, Winter R. Contraception needed to avoid high-fertility-risk births, and maternal and child deaths that would be averted. Farifax: ICF International; 2015.

7. Adegbola O, Okunowo A. Intended postpartum contraceptive use among pregnant and puerperal women at a university teaching hospital. Arch Gynecol Obstet. 2009;280(6):987-92.

8. Federal Democratic Republic of Ethiopia Population Census Commission. Summary and Statistical report of the 2007 population and housing census: population size by age and sex. United Nations Population Fund. 2008.

9. Gebremariam A, Gebremariam H. Contraceptive use among lactating women in Ganta-Afeshum District, Eastern Tigray, Northern Ethiopia, 2015: a cross sectional study. BMC Pregnancy Childbirth. 2017;17(1):421.

10. Abraha TH, Teferra AS, Gelagay AA. Postpartum modern contraceptive use in northern Ethiopia: prevalence and associated factors. Epidemiol Health. 2017;39:e2017012.

11. Gebremedhin AY, Kebede Y, Gelagay AA, Habitu YA. Family planning use and its associated factors among women in the extended postpartum period in Addis Ababa, Ethiopia. Contracept Reprod Med. 2018;3(1):1.

12. Bwazi C, Maluwa A, Chimwaza A, Pindani M. Utilization of postpartum family planning services between six and twelve months of delivery at Ntchisi District Hospital, Malawi. Health. 2014;6(14):1724.

13. Jalang'o R, Thuita F, Barasa SO, Njoroge P. Determinants of contraceptive use among postpartum women in a county hospital in rural KENYA. BMC Public Health. 2017;17(1):604.

14. Rutaremwa G, Kabagenyi A, Wandera SO, Jhamba T, Akiror E, Nviiri HL. Predictors of modern contraceptive use during the postpartum period among women in Uganda: a population-based cross sectional study. BMC Public Health. 2015;15(1):262. 
15. Abera Y, Mengesha ZB, Tessema GA. Postpartum contraceptive use in Gondar town, Northwest Ethiopia: a community based cross-sectional study. BMC Women's Health. 2015;15(1):19.

16. Nigussie A, Girma D, Tura G. Postpartum family planning utilization and associated factors among women who gave birth in the past 12 months, Kebribeyah Town, Somali Region, Eastern Ethiopia. J Women's Health Care. 2016:5:340.

17. Rutaremwa G, Kabagenyi A. Postpartum family planning utilization in Burundi and Rwanda: a comparative analysis of population based crosssectional data. Pan Afr Med J. 2018;30:303.

18. Idowu A, Deji S, Ogunlaja O, Olajide S. Determinants of intention to use post partum family planning among women attending immunization clinic of a tertiary hospital in Nigeria. Am J Public Health Res. 2015;3(4):122-7.

19. Berta M, Feleke A, Abate T, Worku T, Gebrecherkos T. Utilization and associated factors of modern contraceptives during extended postpartum period among women who gave birth in the last 12 months in Gondar Town, northwest Ethiopia. Ethiop J Health Sci. 2018;28(2):207-16.

20. Demie T, Demissew T, Huluka T, Workineh F, Libanos H. Postpartum family planning utilization among postpartum women in public health institutions of Debre Berhan town, Ethiopia. J Women's Health Care. 2018;7(426):2167-0420

21. Gizaw W, Zewdu F, Abuhay M, Bayu H. Extended postpartum modern contraceptive utilization and associated factors among women in Gozamen district, East Gojam Zone, northwest Ethiopia, 2014. Insights Reprod Med. 2017;1(2):8

\section{Publisher's Note}

Springer Nature remains neutral with regard to jurisdictional claims in published maps and institutional affiliations.
Ready to submit your research? Choose BMC and benefit from:

- fast, convenient online submission

- thorough peer review by experienced researchers in your field

- rapid publication on acceptance

- support for research data, including large and complex data types

- gold Open Access which fosters wider collaboration and increased citations

- maximum visibility for your research: over $100 \mathrm{M}$ website views per year

At BMC, research is always in progress.

Learn more biomedcentral.com/submissions 